\title{
ACCELERATOR DEPARTISNT
}

Informal Report

\section{SOME COMMENTS ON AGS BUNCH AREAS}

M.Q. Barton

July 17,1974

\section{Abstract}

Recently, Fainberg and Kalogeropoulos have measured the bunch width in a bunched extracted beam. This width is probably less than rhat of the internal beam. Application of their method to the internal beam is possible.

\section{NOT I C E}

This report was prepared as an account of work sponsored by the Uated States Government. Neither the United States nor the United States Atomic Energy Commission, nor any of their employees, nor any of their contractors, subcontractors, or their employees, makes any warranty, express or implied, or assumes any legal liability or responsibility for the accuracy, completeness or usefulness of any information, apparatus, product or process disclosed, or represents that its use would not infringe privately owned rights. 
In a recent note, Fainoerg and Kalogeropoulos ${ }^{(1)}$ describe measurements of the width of bunches in an external beam extracted via the usual resonant extraction system but with full $r f$ bunching in the AGS. They report a bunch width of $\leqslant 4$ nsec FWHM after correction for their counter resolution. The bunch shape fits a distribution function of $\exp (-|t-220| / 1.7)$. With this function, :he FWHM is actually $2.4 \mathrm{nsec}$ and $95 \%$ of the beam is contained in a base width of 10 nsec.

For ISABELLE, the bunch area is an important parameter. This area can be deduced from the bunch width by the expression

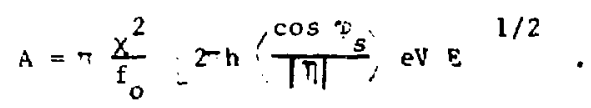

Here $t_{0}$ is the rotation frequency, $h$ the harmonic number, of the stable phase angle, $7=\frac{1}{V^{2}}-\frac{1}{V_{T}^{2}}$ where $\gamma_{T}$ is the transition energy, $e V$ is the peak $r$ energy gain per turn, and $E$ the total energy. $x$ is the half width of the bunch in units of the circumference of the machine. This expression is strictly true only for small oscillations about $\varphi_{s}$. Using

$$
\begin{aligned}
\mathrm{f}_{\mathrm{C}} & =3.7 \times 10^{5} \mathrm{H}_{2} \\
\mathrm{~h} & =1.2 \\
\cos \mathrm{S}_{\mathrm{S}} & =1 \\
\mathrm{eV} & =3.00 \times 10^{5} \mathrm{eV} \\
\mathrm{E} & =30 \times 10^{9} \mathrm{eV} \\
\mathrm{r} & =\frac{1}{0^{2}}-\frac{1}{(8.75)^{2}}=0.01195 \\
X \quad & 5 \times 10^{-9} \mathrm{sec} \times 3.7 \times 10^{5} \mathrm{sec}=1.85 \times 10^{-3}
\end{aligned}
$$

we find

$$
\text { A } \quad \sim 0.2 \mathrm{eV} \mathrm{sec} .
$$

This is smaller than the $0.36 \mathrm{eV} \mathrm{sec} \mathrm{used} \mathrm{for} \mathrm{the} \mathrm{ISABELLE} \mathrm{design} \mathrm{(2)} \mathrm{which}$ was assumed attainable only for lower intensity beams. 
Clearly it is of great interest to know this area. Unfortunately, the bunch width measured in the external beam is probably smaller than what ctrculates in the machine. The mechanism for this difference is as follows: We picture the bunch in the machine as in the sketch

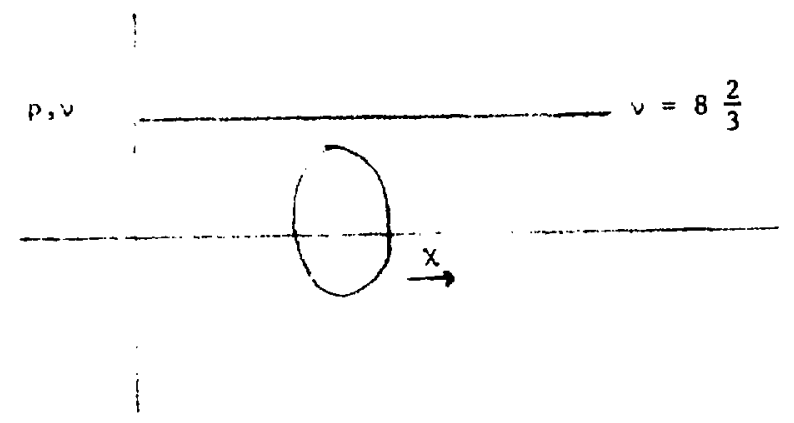

occupying a region in momentum and $x$ space. The vertical axis can also be labelled as vecause of the chronaticity of the machine. For the extraction process, the bunch is moved vertically to the resonance line. Clearly the ellipse containing the particles remaining touches the resonance line at one point and, with this simplified picture, a zero width beam is extracted. Actually, the exact $\nu$ value for resonance extraction depends on the betatron phase space and, therefore, a finite band of particles comes from the top of the ellipse resulting in a pulse width greater than zero but still less than the total width inside the machine. The details of the width can only be worked out if the distributions in the $(p, x)$ and horizontal betatron phase spaces are known along with many parameters of the machine.

This model suggests several comments:

1. If this bunch structure is used for time of flight physics, other parameters of the machlne in addition to obvious $r f$ parameters may need to be controlled and monitored to keep the bunch width stable.

2. Some parameters such as chromaticity can possibly be adjusted to provide further narrowing of the width to enhance the applicability of this method to time of flight applications. 
3. The bunch width results measured externally should not be used to infar the internal bunch structure.

4. The incernal bunch structure could be derived from use of this technique with counters looking at an internal target which is slowly moved vertically into the beam. This target would sample the $(p, x)$ space unsformly and avoid the narrowing which occurs in the extraction process. The method is basically sound and simple with corrections for counter resolution that are no worse than the corrections for bandwidth normally needed for wide band pickup electrodes.

5. Comparison of internal beani and external beam pulse widths might conceivably be of va?ue to study aspects of the extraction process.

\section{References}

1. The AGS Beam Strurcture, A. Fainberg and T.E. Kalogeropoulos, BNL Informal Report 18938 (unpub1ished) 1974.

2. A Proposal for Construction of a Proton-Proton Storage Accelerator Facility - ISABELLE, BNL 18891 (unpublished) 1974, P. 34. 